\title{
FÓRUM
}

Submetido 01.07.2019. Aprovado 14.01.2020

Avaliado pelo sistema double blind review. Editores científicos convidados: Diego M. Coraiola, Amon Barros, Mairi Maclean e Willian M. Foster

Versão traduzida

DOI: http://dx.doi.org/10.1590/So034-759020210103

\section{HISTÓRIAS CORPORATIVAS E A IDEIA DA AMÉRICA LATINA}

\author{
Corporate storytelling and the idea of Latin America \\ Historias corporativas y la idea de América Latina
}

\begin{abstract}
RESUMO
O objetivo deste artigo é contribuir para uma grande variedade de perspectivas teóricas e configurações empíricas para gerar evidências cumulativas sobre a influência de legados históricos e capacidade organizacional para gerenciar o passado. Continuando com a perspectiva crítica que desafia o domínio das epistemologias anglo-saxônicas nos estudos de gestão e organização, realizamos um estudo empírico sobre uma companhia aérea multinacional cujos sucessos passados dependiam das fronteiras norte/ sul anglo-latino-americanas. Analisamos as grandes narrativas da Pan American Airways (PAA) a partir dos arquivos corporativos da empresa a fim de determinar quais os discursos dominantes acerca das pessoas da América Latina. Com base nos temas: política, economia e cultura, apresentamos três grandes narrativas, ou histórias oficiais, que sumariam os discursos da PAA acerca da América Latina entre 1927 e 1960. A partir do feminismo decolonial, buscamos recontextualizar o passado e o discurso hegemônico incorporado nas grandes narrativas do PAA.
\end{abstract}

PALAVRAS-CHAVE | Feminismo decolonial, grandes narrativas, pensamento fronteiriço, América Latina, multinacional americana.

\section{ABSTRACT}

The aim of this article is contributing to a great variety of theoretical perspectives and empirical settings to generate cumulative evidence about the influence of historical legacies and organizational ability for managing the past. In a continuation of critical perspectives that challenges the dominance of Anglo-Saxon onto-epistemologies in management and organization studies (MOS), we conducted an empirical study on a multinational airline company whose past successes depended on the North/South, Anglo/Latin American borderlands. We analyzed the grand narratives of Pan American Airways' (PAA) corporate archival material to determine its dominant discourses about people from Latin America. Based on the three themes of politics, economics, and culture, we present three grand narratives, or official stories, that we argue summaries PAA storytelling about Latin America between 1927 and 1960. Following decolonial feminism, we aim to recontextualize the past and the hegemonic storytelling embedded in PAA's grand narratives.

KEYWORDS I Decolonial feminism, grand narratives, border thinking, Latin America, Pan American Airways

\section{RESUMEN}

El objetivo de este artículo es contribuir a una gran variedad de perspectivas teóricas y escenarios empíricos para generar evidencia acumulada sobre la influencia de los legados históricos y la capacidad organizativa para gestionar el pasado. Continuando con la perspectiva crítica que desafía el dominio de las epistemologías anglosajonas en los estudios de gestión y organizaciones, realizamos un estudio empírico sobre una aerolínea multinacional cuyos éxitos pasados dependieron de las fronteras Norte/ Sur; anglo-latinoamericanas. Analizamos las grandes narrativas del material de archivo corporativo de Pan American Airways (PAA) para establecer discursos dominantes sobre las personas de América Latina. Sobre la base de tres temas: política, economía y cultura, desarrollamos tres grandes narrativas o historias oficiales que argumentamos son un resumen de la narrativa de PAA sobre América Latina entre 1927 y 1960. Utilizando el marco teórico del feminismo decolonial, nuestro objetivo es recontextualizar el pasado y la narración hegemónica incrustada en las grandes narrativas de PAA.

PALABRAS CLAVE / Feminismo decolonial, grandes narrativas, pensamiento fronterizo, América Latina, multinacional estadounidense. 


\section{INTRODUÇÃO}

Este artigo contribui para a pesquisa decolonial e feminista ao conduzir um estudo empírico de uma empresa multinacional, a Pan American Airways (PAA), a qual estrategicamente construiu e usou a história para vender a ideia de América Latina e gerenciar sua marca, influenciando retratos do passado, presente e futuro de latino-americanos. Continuando com a perspectivas crítica que desafia o domínio das epistemologias anglo-saxônicas nos estudos de gestão e organização (Gantman, Yousfi, \& Alcadipani, 2015; Ibarra-Colado, 2006, 2008), este estudo desafia os sucessos de uma organização cujos sucessos do passado dependiam do norte/sul e das fronteiras anglo-latino-americanas.

Anzaldúa desenvolveu uma teoria feminista amplamente utilizada em campos como filosofia, estudos raciais, estudos culturais e estudos queer, que foi recentemente reconhecida por outras estudiosas organizacionais feministas (Calás \& Smircich, 2013). 0 trabalho de Anzaldúa examina dois fatores que são relevantes para o estudo de gestão, história e organizações: 1) ela apresenta uma teorização das interseções de raça, classe, gênero e nação; e 2) faz uma análise histórica para compreender a relação EUA-América Latina ao longo do tempo. Por outro lado, estudiosos organizacionais decoloniais (tais como Alcadipani \& Faria, 2014) usam o trabalho de Mignolo $(2005,2011)$ para incorporar uma perspectiva latino-americana em suas pesquisas. Mignolo fornece uma leitura crítica da história da América Latina, desde a conquista da terra pela Espanha no século XV até a conquista da hegemonia cultural e política sobre a região pelos Estados Unidos no século XX.

Nas seções seguintes, delineamos como a PAA narrativizou e representou a América Latina, abordando a internacionalização de uma multinacional anglo-saxônica na geopolítica latinoamericana. Para isso, analisamos as grandes narrativas (Boje, 2001) dos materiais de arquivo corporativo da PAA para estabelecer os discursos dominantes sobre os latinos. Com base nos temas da política, economia e cultura, desenvolvemos três grandes narrativas, ou histórias oficiais, que argumentamos resumir a narrativa da PAA sobre a América Latina entre 1927 e 1960.

\section{QUADRO TEÓRICO}

Este trabalho reúne uma pesquisa histórica e arquivística para examinar a história como um recurso estratégico utilizado por uma empresa multinacional. Este artigo reuniu o estudo do passado, pesquisa em arquivos e o estudo da história como um recurso estratégico utilizado por uma empresa multinacional. Este estudo sobre a PAA-América Latina foi conduzido sob dois pressupostos pós-positivistas principais: 1) o passado, na pesquisa em arquivos, permanece ontologicamente indisponível (Mills \& Helms Mills, 2017); e 2) a história é a tentativa de reproduzir o passado por meio de narrativas ou crônicas (descrições de eventos). Em outras palavras, os dados que coletamos servem para interpretar o passado e representar (desconstruir e reconstruir) a história. Assim, consideramos o arquivo do PAA como um local para construir uma representação plausível do passado. Para Hedstrom (2002), existem muitos fatores importantes relacionados à memória e é importante que os pesquisadores considerem o poder dos arquivistas sobre as memórias históricas. Estudiosos organizacionais que realizam pesquisa em arquivos devem reconhecer o processo pelo qual organizações e gerentes organizam e apresentam conhecimento para determinado público (Foster, Coraiola, Suddaby, Kroezen, \& Chandler, 2017).

A criação de conhecimento a partir do passado é influenciada por contribuições de teorias decoloniais e feministas (Anzaldúa, 2007), historiografia (White, 2009), análise narrativa (Boje, 2001, 2008a) e conhecimento narrativo (Lyotard, 1987).

A literatura sobre estudos coloniais pode ser dividida em dois grandes grupos (Miñoso \& Castelli, 2011, p. 196). Este primeiro é composto pelo grupo subalterno do Sul da Ásia que criticam a hegemonia e dominação do Ocidente, e o grupo de estudos pós-coloniais, o qual inclui Fanon, Spivak e Mohanty, os quais realizam pesquisas nas colônias francesas e inglesas na África, Caribe e Índia. O segundo grande grupo é formado por estudiosos críticos da América Latina que emergiram na década de 1950, tais como Quijano, Amin, Dos Santos e Dussel, e mais recentemente estudiosos decoloniais como Mignolo, Fernandez Retamas, Montero, Rodriguez, Castro Gomez, Mendietta, Grosfoguel e Rivera Cusicanuqui. Entre os estudiosos decoloniais, optamos por seguir a pesquisa de Mignolo (2011), que defende um movimento que vai além do pós-colonialismo que acarreta deslocamento, mudança e uma passagem do póscolonial (após colonial) para o decolonial (além do colonial) (Mignolo \& Tlostanova, 2006, p. 206). Três ideias principais de Mignolo foram importantes para este estudo: 1) no século XVIII, os "latino-americanos" eram identificados como não anglo-europeus e não europeus; 2) a crise econômica e política que atingiu a América "Latina" na década de 1950 reforçou seu sentimento de inferioridade e extinguiu por muitos anos qualquer expectativa de que a América Latina se tornasse uma região emergente; 3) os impérios que colonizaram as Américas influenciaram o próprio processo de colonização. A América 
do Norte foi colonizada por dois impérios em ascensão, o britânico e o francês, enquanto a América do Sul foi colonizada por espanhóis e portugueses, dois impérios que estavam em declínio. Essas três ideias demonstram a importância de estudar outras formas de criação de conhecimento ou "pensamento de fronteira" (Anzaldúa, 2007), pois é importante desmascarar a legitimação do conhecimento ocidental acima de todas as outras raízes do conhecimento. 0 conceito de pensamento de fronteira, tratado pela primeira vez por Gloria Anzaldúa em Borderlands/La Frontera (2007), é importante para o estudo da decolonialidade (Mignolo, 2000, 2002, 2007). Para Mignolo, o pensamento de fronteira é necessário para quebrar a superioridade/hegemonia do conhecimento ocidental e eliminar a ideia de um centro e uma periferia. Por meio do pensamento de fronteira, vamos além da crítica pós-colonial e caminhamos em direção à decolonialidade do conhecimento que elimina o legado colonial. Assim, "o pensamento de fronteira é a epistemologia da exterioridade; isto é, do exterior criado a partir do interior" (Mignolo \& Tlostanova, 2006, p. 206).

Perspectivas feministas decoloniais (Anzaldúa, 2007; Mohanty, 1984, 1991, 2003, 2008) desenvolveram maneiras de examinar várias dualidades criadas pelas sociedades europeias e americanas e o sistema hierárquico que é formado quando múltiplas díades - raça e gênero e classe e nação, em vez de raça ou gênero ou classe ou nação - são reunidos para análise. Este tipo de trabalho explora o que Lugones (2015) chama de epistemologías de fronteras (epistemologias de fronteira) ou o que Anzaldúa (2007) chama de fronteiras/fronteras. Ambos os estudiosos analisam a distinção entre moderno/não moderno, colonial/decolonial e nós/eles. Anzaldúa (2007) refere-se ao pensamento de fronteira como uma nova consciência (feminina) que ocorre em sete estágios: 1) ruptura consciente com todas as tradições opressoras de todas as culturas e religiões; 2) documentação da ruptura; 3) reinterpretar a história usando novos símbolos e formar novas perspectivas em torno de pessoas de pele escura, mulheres e pessoas queer; 4) desenvolver tolerância à ambiguidade; 5) desenvolver abertura para compartilhar e novas formas de pensar, render-se a noções de segurança/familiar; 6) desconstruir/construir história; e 7) se tornar um Nahual; isto é, transformar-se em outra pessoa ou animal.

Uma abordagem de pensamento de fronteira aprimora o pensamento crítico, a contextualização histórica, a compreensão da ambiguidade e a capacidade de transformar o status quo. Essa transformação nos lembra que falamos de um determinado local dentro de uma estrutura de poder a qual, para Anzaldúa (2007), é interseccionada por classe, raça e gênero. Essa interseccionalidade intrínseca torna visíveis as muitas opressões que as mulheres negras enfrentaram ao longo da história (Erel, Haritaworn, Rodriguez, \& Klesse, 2011). As vivências do sujeito geram a necessidade de uma abordagem de pensamento de fronteira (Mignolo, 2011) que possa romper o código ocidental e trazer o lócus de enunciação "Eu estou onde faço e penso" (Mignolo, 2011, xvi). Usar uma estrutura feminista decolonial dá voz ao "silêncio dos arquivos" (Decker, 2013) ao se concentrar na criação de uma imagem masculina no passado latino-americano que foi amplamente esquecido na gestão e no conhecimento organizacional.

\section{METODOLOGIA}

A estrutura teórica do feminismo decolonial destaca o desequilíbrio material e simbólico de poder entre as mulheres ocidentais e não ocidentais ao longo da história ocidental e como essa diferença configurou uma hierarquia na qual as últimas estão em desvantagem em vários aspectos por serem mulheres e pessoas não ocidentais (Latinas, Asiáticos, Indianos, etc.). Conforme descrito na figura 1 a seguir, combinamos três conceitos da estrutura feminista decolonial para completar este trabalho: 1) revisionismo histórico; 2) um exame das relações hierárquicas, poder e colonialidade; e 3) um exame de como gênero, raça e nação se desenvolvem ao longo da história. Uma grande análise narrativa foi usada para explorar como o PAA produziu histórias dominantes sobre a América Latina. Uma análise anti-narrativa desconstrói essas histórias e mostra as contradições, lacunas e histórias não contadas na narrativa. A análise exigiu a análise do material da PAA e dos eventos históricos que ocorreram entre seu primeiro voo em 1927 e a mudança das relações internacionais dos EUA com a América Latina quando John F. Kennedy tornou-se presidente dos EUA em 1960.

O uso da análise de grandes narrativas de Boje (2001) desmantela a narrativa unilateral da América Latina nas revistas, livretos e boletins da PAA. Grandes narrativas ilustram claramente o discurso unilateral da PAA e mostram como ele legitimou o conhecimento do passado (Lyotard, 1987). Tomando como base Boje (2001, 2008a, 2008b) e uma análise temática, descrevemos três grandes narrativas sobre a América Latina que foram recorrentes no material estudado entre os anos de 1927 e 1960. Mostramos que essas grandes narrativas se sobrepõem ao longo do tempo e as apresentamos de acordo com uma cronologia de eventos sociopolíticos (Mills, 2010) que influenciaram as relações EUA-América Latina (Figura 2). 
Figura 1. Referencial teórico e métodos de análise no estudo de caso da PAA

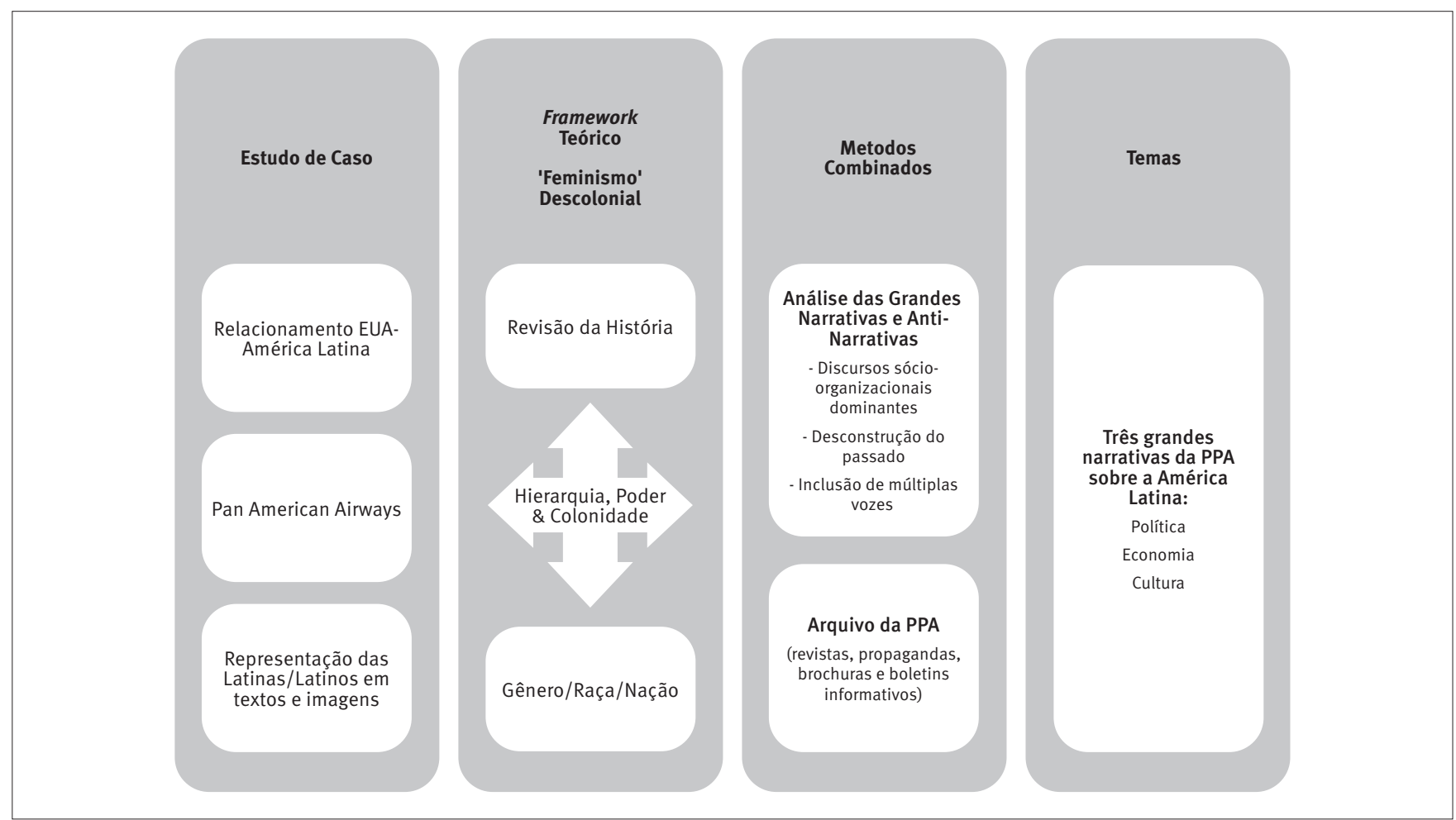

Figura 2. Contexto socio-histórico que influenciou as Grandes Narrativas da PAA entre 1927 e 1960

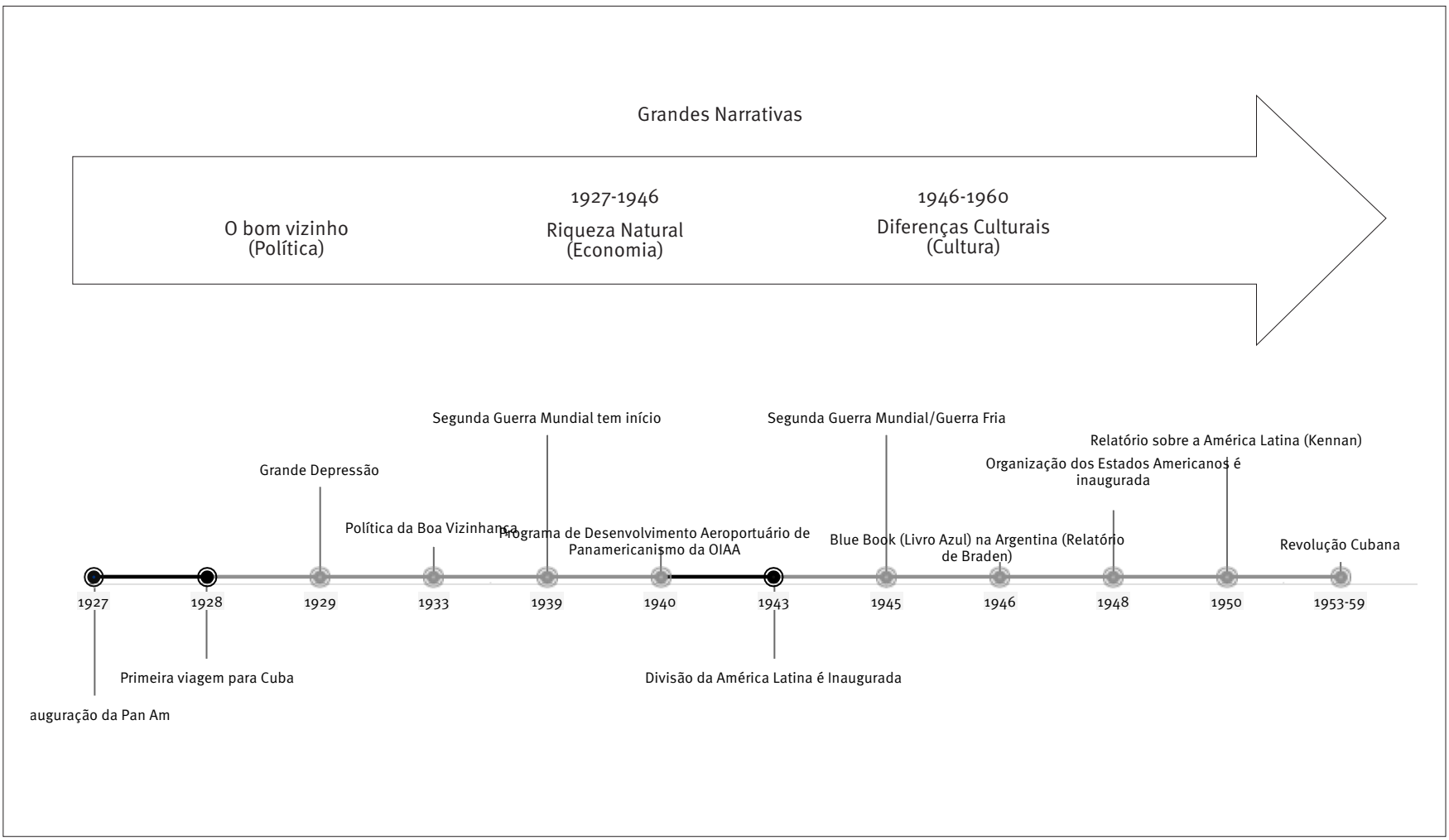


A criação de grandes narrativas envolveu revisar e questionar “a verdade" e seu significado na história mundial e reconhecer que atualmente conhecemos apenas "metade da história" (Mignolo, 2011, p. 182). Usando uma grande análise narrativa, fomos capazes de revisar e capturar os discursos dominantes que criaram "a verdade" sobre a América Latina. Devido ao hábil desenvolvimento de narrativas históricas da PAA, essa pesquisa exigiu certo grau de ceticismo e uma busca por anti-narrativas em textos, imagens e acontecimentos históricos para explorar o outro lado da história. As anti-narrativas desafiam a grande narrativa ou narrativa organizacional que controla os eventos organizacionais e seu significado (Vaara \& Tienari, 2011) ao introduzir novos atores (por exemplo, Argentina), histórias fragmentadas (por exemplo, a democratização da política latino-americana) e histórias plausíveis (por exemplo, o cosmopolitismo na América do Sul).

\section{ANÁLISE DE GRANDE NARRATIVA DA PAN AMERICAN AIRWAYS}

\section{A grande narrativa do bom vizinho}

Na primeira metade do século XX, houve várias turbulências à nível mundial. A crise econômica da Grande Depressão e duas guerras mundiais remodelaram o mapa mundial. Os EUA se tornaram a potência geopolítica dominante (ao lado da URSS) na era pós-Segunda Guerra Mundial, implementando grandes mudanças políticas e econômicas.

Os Estados Unidos exerceram um papel dominante na política internacional por meio de diversos instrumentos políticos que, direta e indiretamente, envolveram as nações latino-americanas.

A PAA começou a promover a boa vizinhança no início dos anos 1930, antes de Franklin D. Roosevelt (FDR) criar a política de boa vizinhança do governo dos Estados Unidos. A grande narrativa do bom vizinho foi implementada para incentivar o transporte aéreo e conectar as nações do hemisfério ocidental, enquanto aumenta a influência política e econômica dos EUA na América Latina (Van Vleck, 2013). A política da Boa Vizinhança, lançada pelo governo dos Estados Unidos em 1933, afirmava que os Estados Unidos não implementariam uma intervenção militar em território latinoamericano; em vez disso, estreitaria a amizade entre as nações da região. A narrativa de estabelecer e manter boas relações com as nações vizinhas posteriormente influenciou a visão romântica dos latino-americanos, está ligada à desconfiança política entre os EUA e a América Latina e tem origem na Doutrina Monroe de 1823. A Doutrina Monroe tinha como objetivo impedir os esforços europeus de colonizar os Estados Unidos e o restante do continente americano. No entanto, um Corolário Roosevelt para a Doutrina Monroe foi criado em 1904 durante a presidência de Theodore Roosevelt, sendo saudado como a política do big stick dos EUA. Esse corolário deu aos Estados Unidos o direito de proteger seus cidadãos por meio de intervenção militar, mesmo nos casos em que tais perigos fossem apenas previstos (ou seja, de forma oposta às atividades reais das potências europeias). Na prática, Washington interveio militarmente na América Latina uma dúzia de vezes durante o primeiro trimestre do século XX (intervenções militares no Haiti, de 1915 a 1930, e na República Dominicana, de 1916 a 1924, etc.) (Patel, 2016).

O programa de FDR marcou a transição de uma política intervencionista militar (o Corolário de Roosevelt para a Doutrina Monroe) para a política de boa vizinhança: “Tudo o que este país [os EUA] deseja é ver os países vizinhos estáveis, ordeiros e prósperos" e "Qualquer país cujo povo se conduza bem pode contar com nossa sincera amizade" (Holden \& Zolov, 2011, p. 97).

\section{Figura 3. Os vizinhos latinos na grande narrativa da PAA}

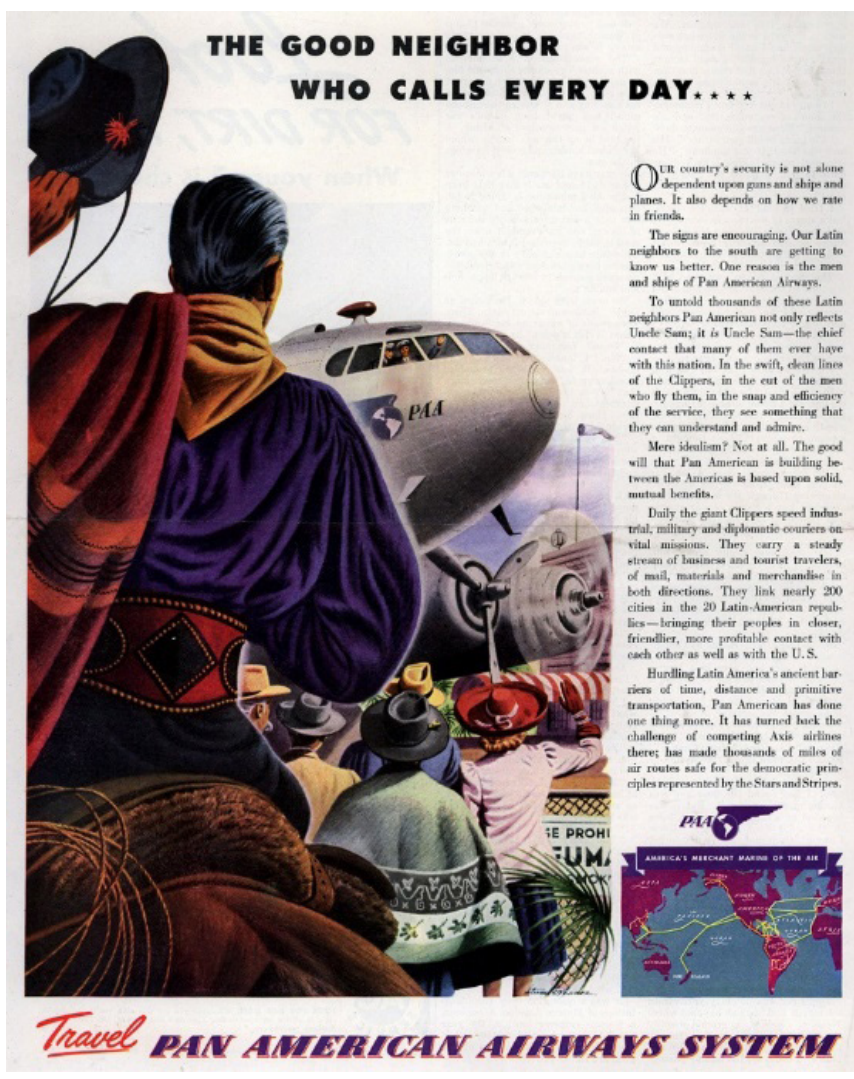

Fonte: Anúncio da Pan American Airways (1941).

A partir de 1933, a política da Boa Vizinhança passou a ser mencionada diretamente na publicidade corporativa da PAA. A política foi enfatizada durante os anos entre guerras e então 
estrategicamente durante a Segunda Guerra Mundial; os EUA suspeitavam que grande parte da América Latina fosse pró-Eixo ou pelo menos suscetível a tal influência (Bethell \& Roxborough, 1988). Como visto em um anúncio (figura 3), a PAA se identificou como "O Bom Vizinho que Liga Todos os Dias" e diz ao leitor que a segurança dos EUA não apenas "depende de armas, navios e aviões", mas também de "como nós (os EUA) avaliamos os amigos". Além disso, aos olhos dos latino-americanos, a PAA “não reflete apenas o Tio Sam; é o Tio Sam - o principal contato que muitos deles já tiveram com esta nação.” A PAA conclui o anúncio compartilhando anti-narrativas (histórias fragmentadas) que explicam como a grande narrativa do bom vizinho acomoda o plano político da Segunda Guerra Mundial contra o Eixo; entretanto, também descreve a América Latina como atrasada, carente e inferior quando comparada aos seus homólogos Anglo-saxão/ do Norte/Ocidental/EUA/PAA. De acordo com o texto do anúncio,

Enfrentando as antigas barreiras de tempo, distância e transporte primitivo da América Latina, a PAA fez mais uma coisa. Ela retomou o desafio das companhias aéreas concorrentes do Eixo lá; tornou milhares de milhas de rotas aéreas seguras para os princípios democráticos representados pela bandeira dos Estados Unidos.

Durante a década de 1940, o governo dos Estados Unidos mobilizou a grande narrativa do bom vizinho criando programas, legislações e programas educacionais que estreitaram a amizade e a colaboração e ofereceram ajuda econômica e consultoria especializada às repúblicas latino-americanas (Interdepartmental Committee on Cooperation with the American Republics [ICCAR], 1940).

\section{Figura 4. Um retrato da América Latina e seu povo}

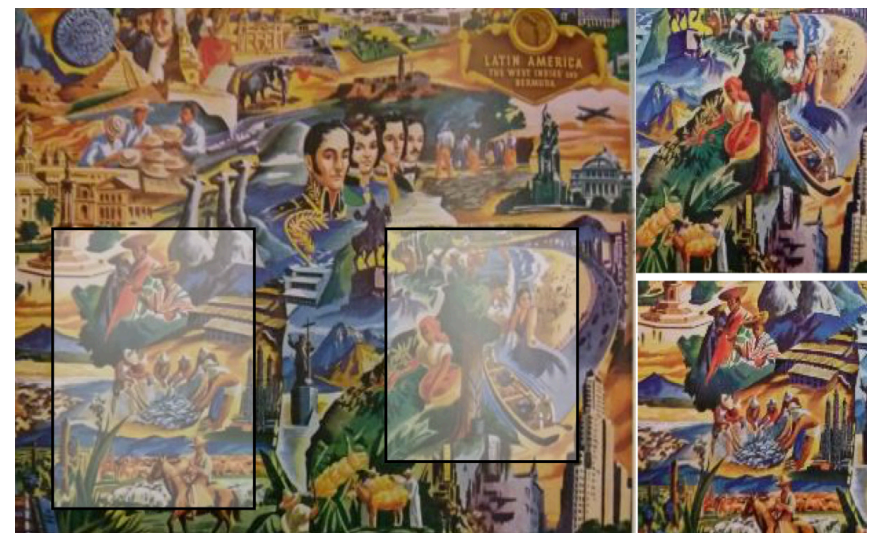

Fonte: Pan American Airways (1946d).
Um guia turístico, "A World of Neighbors" (Um Mundo de Vizinhos, em português), apresenta várias imagens da região usando uma ilustração composta por vários estilos de artefatos culturais, reduzida a meia página, com a legenda: “Um retrato da América Latina, Índias Ocidentais e Bermudas, parte de Um Mundo de Vizinhos." (Pan American Airways, 1946d) (Figura 4).

Este retrato ilustra um pastiche de artefatos simbólicos na tentativa de representar a diversidade cultural de uma região desconhecida para os turistas anglo-americanos. No centro desta imagem estão os líderes da independência de Espanha e Portugal, o que mostra um traço de colonialismo. 0 retrato masculino da América Latina mostra três mulheres e onze homens. A pós-colonialidade do PAA é generalizada, já que as latinas são comumente representadas de duas maneiras: são mostradas como domésticas (submissas) e como artistas, mostrando sensualidade por meio da dança.

A superioridade cultural dos EUA está presente na narrativa da PAA; "As rotas da Pan American World Airways System podem mostrar abaixo dele [o turista] todo o panorama do passado, presente e indicações do futuro dessas terras" (Pan American Airways, 1946d, p. 20). Nessa narrativa, a pós-colonialidade surge da seguinte forma: o passageiro é considerado um homem branco/anglo-saxão (ele). A América Latina está abaixo dele, portanto inferior ao homem anglo-americano. Além disso, há uma representação do passado e um futuro plausível, onde a ideia de que a PAA é o futuro no presente aparece implícita, já que a PAA é pioneira em tecnologia, aviação comercial e rotas de conexão na América Latina:

Ilhas do Caribe, onde as caravelas de Colombo surfaram nas ondas e Morgan e o Capitão Kidd assombram as areias de coral. A América Latina havia sido tocada por exploradores e caçadores de tesouros europeus... Grande parte da América Latina tinha colônias quase um século antes dos primeiros colonizadores ingleses permanentes desembarcarem em Plymouth Rock em 1620. (Pan American Airways, 1946d, p. 20)

A PAA igualou o passado latino-americano com a conquista europeia, chamando amigavelmente os europeus de "exploradores". A narrativa europeia da "descoberta" da América por Colombo passa a ser a narrativa da PAA. No entanto, a invenção da América (Mignolo, 2005) é um lembrete da existência de culturas pré-colombianas que precederam os exploradores europeus. Em um esforço para seduzir o viajante anglo-saxão e europeu, a PAA elaborou várias narrativas de latino-americanos 
como bons vizinhos e, assim, explorou certas imagens, ideias e temas, incluindo natureza, cultura, o passado colonial e a vida urbana versus rural (Pan American Airways, 1946d).

A América Latina foi retratada como uma terra de gaúchos, à qual foram transplantadas cidades europeias, tais como Madrid, e uma terra de impérios (como o Inca) que não existem mais. Essas representações foram elementos usados na narrativa da América Latina, a qual a PAA elaborou fazendo malabarismos com uma noção de tempo (passado pré-colonial e colonial), geografia (Madri/Europa) e o binário de semelhante - diferente (folk/gaúchos). A colonização europeia foi importante para a construção da grande narrativa da boa vizinhança, pois conferiu aos EUA um sentimento de direito às nações sul-americanas cujos cidadãos tinham mais ascendência branca do que caribenha ou afro-ascendência.

Um livreto da PAA, que conta a história dos 17 anos de experiência da PAA voando com os Clippers durante os anos da Segunda Guerra Mundial, é permeado pela grande narrativa do bom vizinho e perpetua um sutil senso de direito da PAA. Em uma manchete, "Nossos bons vizinhos do sul", a PAA parabeniza suas companhias aéreas associadas na América Latina:

Desde o início da empresa - em 1927 - a Pan American buscou não controlar o ar... mas sim ajudar e aconselhar nossos "Bons Vizinhos" na formação de suas próprias companhias aéreas nacionais. (Pan American Airways, 1945C, p. 13)

A tradição norte-americana de paternalismo em relação aos países latino-americanos (Patel, 2016) sustenta seu papel como conselheiros e provedores de ajuda. A história da guerra mexicana-anglo-americana de 1845-48 parecia há muito esquecida pelos EUA em uma descrição do México feita pela PAA:

"A Rainha das Cidades" uma praça na Cidade do México vista do céu... A capital de nossos "Bons Vizinhos" mais próximos ao sul tem dois milhões de habitantes, lindas avenidas, uma atmosfera verdadeiramente internacional. (Pan American Airways, 1945C, p. 15)

Durante as primeiras décadas do século XX. através da ideologia do pan-americanismo, a produção de representações dos países da América do Sul aumentou (Salvatore, 1998) e passou por várias iterações: antes vistos como ameaça para os EUA (Durepos, Helms Mills, \& Mills, 2008), passaram a ser vistos como bons vizinhos.
Posteriormente, as contra-narrativas emergiram como histórias alternativas à grande narrativa da PAA. A primeira que surgiu revelava que a América Latina é um bom negócio para a PAA: “uma vasta área duas vezes e meia o tamanho dos Estados Unidos continental e o lar de 130 milhões de bons vizinhos" (Pan American Airways, 1946b). De acordo com um artigo da revista PAA, “Como o 'comércio amigável' com os vizinhos ajuda a economizar dinheiro dos contribuintes dos EUA", a América Latina representou um mercado que ofereceu benefícios econômicos para os cidadãos dos EUA após a Segunda Guerra Mundial (Pan American Airways, 1958). Outra contra-narrativa se esconde por trás da necessidade da PAA de "tornar verdadeiros vizinhos" países da América do Sul, como a Argentina, que tinha um histórico de confrontos com os Estados Unidos. Essa narrativa de boa vontade pretendia mascarar intervenções militares anteriores em território latino-americano e as tensões diplomáticas entre os Estados Unidos e várias nações latino-americanas.

\section{A grande narrativa da riqueza natural}

Após a Segunda Guerra Mundial, a expansão da PAA para a região da América Latina refletiu duas coisas: novos avanços tecnológicos (por exemplo, o avião a jato) e uma mudança no comércio com a América Latina, na qual a Europa perdeu poder comercial e influência contra os EUA. A grande narrativa da riqueza natural via a América Latina como fornecedora de recursos naturais para um crescente mercado norte-americano pós-Segunda Guerra Mundial. O outro lado dessa grande narrativa foi a auto-representação da PAA como tecnologicamente superior aos latino-americanos. A grande narrativa do bom vizinho, que ainda promovia uma amizade política entre os EUA e os latinoamericanos, se sobrepôs e coexistiu com histórias sobre a América Latina como fonte de riqueza natural e recursos ilimitados que atenderiam às necessidades dos compradores norte-americanos. De fato, a boa vizinhança ajudou o continente americano a se recuperar da crise econômica graças à Lei do Acordo de Comércio Recíproco de 1934 (Argentina e outras nações ficaram de fora); o valor do dólar comercial dos EUA com a América Latina triplicou entre 1934 e 1941 (Patel, 2016).

Várias revistas descreveram a importância de aprofundar os laços comerciais com as nações latinas. Por exemplo, um calendário promocional, "The Wealth of the Other Americas - A Riqueza das Outras Américas, em português" (Pan American Airways, 1945b), previu a abertura do comércio entre os EUA e a América Latina, região que foi um "fator importante na expansão do comércio exterior dos EUA após a guerra" (Pan American 
Airways, 1945b, p. 4). A expansão do comércio dos Estados Unidos foi desafiada pela concorrência europeia e pelo fato de a América Latina ser o único mercado aberto em 1946. Com isso, a PAA executou um plano para se tornar o principal trader entre os países latino-americanos, criando voos mais rápidos e baratos entre Nova York e as cidades sul-americanas para competir com as rotas das cidades europeias. (Pan American Airways, 1946a). Por exemplo, a PAA lançou um voo com duração de 38 horas entre Nova York e Buenos Aires, o que se tornou um marco para os negócios internacionais. Este novo serviço estava alinhado com a narrativa americana do pan-americanismo que dominou os anos entre guerras (Schoultz, 1998, p. 318) e com o momento histórico no qual os EUA reestruturaram a economia mundial (Pan American Airways, 1946c) quebrando a dependência da Argentina do comércio europeu.

De muitas maneiras, o sistema capitalista se traduziu na narrativa da riqueza natural da PAA. Por exemplo, a Clipper cargo ajudou empresas locais a vender produtos fora da América do Norte, desde pintinhos a produtos congelados (Pan American Airways, 1957b). A comercialização de diamantes do Brasil, maior produtor de diamantes depois da África do Sul, reflete o envolvimento das elites latino-americanas na construção da narrativa capitalista. De fato, o governo brasileiro patrocinou a Panair do Brasil (associada a PAA) para "acelerar o tráfego" do negócio de diamantes (Pan American Airways, 1945a, p. 26). Enquanto isso, a grande narrativa da riqueza natural descreve a) a América Latina como fornecedora de frutas exóticas e nativas e matérias-primas (diamantes) e b) a América do Norte como exportadora de produtos, principalmente os industrializados.

A grande narrativa do bom vizinho complementou a grande narrativa da riqueza natural ao intensificar o comércio entre os EUA e a América Latina, transformando assim a economia global de tal forma que o Brasil se tornou mais importante para os Estados Unidos do que a França e Cuba para a Holanda (Patel, 2016). Através do olhar das dualidades pós-coloniais, a América Latina foi colonizada, representando o mundo natural e lar dos povos nativos. Por outro lado, a América do Norte era o colonizador trabalhador, uma região com cidadãos ao invés de nativos. Um dos livretos da PAA explicava aos clientes da PAA como era importante ter o Brasil como fornecedor de borracha:

Todo mundo sabe o que aconteceu com nosso suprimento de borracha quando os japoneses tomaram as Índias Orientais e a Península Malaia. Algumas pessoas sabem que os melhores pneus de borracha sintética não podem ser feitos sem adicionar um pouco de borracha natural. Mas poucas pessoas percebem que a Pan American tem transportado látex (borracha natural) do Brasil para os Estados Unidos (Pan American Airways, 1945C, p. 17).

A expansão da PAA também reagiu aos acordos políticos entre os Estados Unidos, América Latina e Europa. Por exemplo, a incorporação de Barbados à Divisão Latino-Americana da PAA exigiu a permissão do Conselho de Aeronáutica Civil dos Estados Unidos (1948) e a aprovação do Reino Unido, visto que Barbados foi uma colônia do Império Britânico até 1966 (Pan American Airways, 1957b). No período pré-guerra, a PAA conseguiu evitar a interferência do governo negociando "seus próprios contratos de desembarque na América do Sul” (Pan American Airways, 1946a). Durante os anos de guerra, a PAA esteve diretamente envolvida na construção de aeroportos na região da América Latina. A PAA conseguiu construir aeroportos militares na selva brasileira devido a contratos secretos do governo, e "quando acabou a guerra, a PAA havia construído cinquenta aeroportos em quinze países” (Pan American Airways, 1996, p. 167).

No livreto de 37 páginas, "The wealth of the other America - A riqueza da Outra América, em português”, a PAA divulga o impacto das viagens aéreas no comércio e na troca comercial com vinte países latino-americanos além dos Estados Unidos. Os mercados latino-americanos são descritos como fornecedores subdesenvolvidos de matérias-primas, mas também como ricos:

[cidades portuárias] são separadas umas das outras por grandes distâncias de áreas subdesenvolvidas e, em alguns casos, inexploradas; elas têm servido simplesmente como centros de comércio onde matérias-primas dos distritos agrícolas e de mineração adjacentes podem ser enviadas para o exterior em troca de artigos manufaturados.

Quando a Segunda Guerra Mundial separou as Nações Unidas de suas fontes usuais de matériaprima, eles olharam para a América Latina com sua riqueza em alimentos, peles, lã e algodão, e seus minerais como cobre, óleo, cromo, antimônio e manganês. (Pan American Airways, 1943, p. 4)

A co-dependência comercial no relacionamento EUAAmérica Latina após a Segunda Guerra Mundial e o papel fundamental da PAA no avanço de suas viagens aéreas comerciais ajudaram a grande narrativa da riqueza natural a ganhar vida. 
A PAA ajudou a "abrir caminho" para esta nova era na América Latina. Com suas companhias aéreas associadas, conseguiu superar as barreiras naturais que escondiam a riqueza dos países (Pan American Airways, 1943, p. 5).

\section{A grande narrativa da diferença cultural}

Os negócios da PAA na América Latina estavam ligados às consequências políticas contemporâneas da Segunda Guerra Mundial, um mundo dividido entre dois grupos de super-alianças: o Eixo (Alemanha, Itália, Japão, Hungria, Romênia e Bulgária) e os Aliados (Estados Unidos, Grã-Bretanha, França, URSS, Austrália, Bélgica, Brasil, Canadá, China, Dinamarca, Grécia, Holanda, Nova Zelândia, Noruega, Polônia, África do Sul e Iugoslávia). Os Aliados se retrataram como os países com liberdade de expressão, imprensa e associação. Já as potências do Eixo eram portadoras de ideologias nazistas e fascistas. Como a PAA era uma empresa sediada nos Estados Unidos e que tinha voos em todo o mundo, tornou-se um aliado das relações exteriores dos Estados Unidos durante a segunda guerra mundial: “A guerra era um negócio especialmente para a Pan Am, com metade de seus contratos sendo com o exércitos dos Estados Unidos e cujas receitas durante os quatro os anos de guerra aumentaram 75\%" (Bender \& Altschul, 1982, p. 366).

O monopólio da PAA na América Latina teve implicações em diferentes setores. Uma dessas indústrias foi a de transporte, onde o transporte terrestre e marítimo foi substituído pelo aéreo, e a outra o comércio e as atividades comerciais, que sofreram grandes mudanças devido ao transporte mais rápido de mercadorias possibilitado pelo avião a jato. Além disso, as viagens aéreas revolucionaram a indústria de viagens ao criar uma nova identidade de viagens: o turista aéreo. Porém, não havia demanda por viagens aéreas, e a PAA teve que criar um mercado para a América Latina. A PAA era a única companhia aérea que voava para fora dos Estados Unidos antes da Segunda Guerra Mundial e, portanto, tornou-se um recurso especializado e fonte de informações sobre a geografia e as pessoas da América Latina. O processo que a PAA empreendeu para entender os eventos históricos e as características culturais dos países latinoamericanos está refletido em documentos como "Observations on U.S. Policy toward Latin America” (Observações sobre a política dos Estados Unidos para a América Latina, em português), da Divisão Latino-americana da PAA (Pan American Airways, 1961).

Durante a Segunda Guerra Mundial, os EUA apoiaram os ditadores latino-americanos tanto financeira quanto legalmente (Schoultz, 1998), mas a situação mudou com o discurso dos EUA sobre democratização. A grande narrativa da boa vizinhança em relação às nações latino-americanas vigente até então tornou-se um discurso de democratização das repúblicas latinas e tolerância zero aos ditadores (por exemplo, Getúlio Vargas no Brasil ou Rafael Trujillo na República Dominicana) (Schoultz, 1998). Na década de 1950, as representações dos Estados Unidos dos latino-americanos como bons vizinhos se sobrepuseram às representações deles como anti-democráticos, caóticos, grandiloquentes e fortemente masculinos. A grande narrativa do bom vizinho estava se transformando porque, desde 1957 , os Estados Unidos desenvolviam uma relação conflituosa com ditadores como Trujillo na República Dominicana. No entanto, a PAA continuou trabalhando com Trujillo e seu regime até seu assassinato (1961). Além disso, em 1961 estava claro que a Doutrina Monroe continuava em vigor pela Organização do Estado Americano (Organization of the American State - OAS), cuja criação após a Segunda Guerra Mundial intensificou a busca contínua do governo dos Estados Unidos pelo domínio das nações latino-americanas pelos Estados Unidos. Isso pode ser visto na imposição de sanções sem precedentes ao regime de Trujillo pela OEA (Roorda, 1998).

Um relatório chocante foi publicado em 1950, durante a presidência de HS Truman. O relatório crítico e opinativo de George Kennan tornou-se a narrativa que descrevia as ditaduras e governos populistas das nações latino-americanas. Sua explicação do comportamento das pessoas baseada no caráter descreveu os latinos como egoístas egocêntricos com "um desejo patético de criar a ilusão de coragem desesperada, inteligência suprema e uma virilidade ilimitada, onde as virtudes mais construtivas são tão visivelmente ausentes" (Schoultz, 1998, p. 330).

Uma distinção fundamental do deslocamento latino e anglo-saxão, além do caráter nacional, da língua e da herança europeia, é a cor da pele. Os europeus foram os primeiros a categorizar sistematicamente o mundo e seu povo de acordo com a cor da pele e a criar um continuum do superior ao inferior, da brancura à escuridão, e o resto do mundo ocidental rapidamente seguiu o exemplo. Os materiais oficiais da PAA retratam principalmente a raça através do uso da linguagem, em particular usando o termo nativos para se referir aos latinoamericanos e imagens de mulheres e homens de pele escura. As narrativas da PAA lembram contos dos primeiros conquistadores europeus; isto é, os contos de descoberta, fascinação, diferença racial e culturas estranhas. As primeiras viagens da PAA fora dos Estados Unidos solidificaram as narrativas norte-americanas da etnia latino-americana, estabelecendo a imagem dos latinos morenos. 
A grande narrativa da diferença cultural fortalece duas ideias desenvolvidas por Mignolo (2005): a ideia de que um novo continente nasceu e a reconfiguração do processo de decolonização da Europa nas Américas.

Essa grande narrativa foi solidificada como uma estratégia corporativa para diversificar o mercado latinoamericano para o público anglo-saxão, e os guias turísticos da PAA ilustram uma ligação clara com o passado colonial britânico e espanhol das Américas. A divisão das Américas entre o espanhol e o inglês também criou uma divisão entre as culturas latina e anglo-saxã. Comparando como a PAA descreve os ingleses e os espanhóis, e depois analizando como eles fazem o mesmo com seus territórios colonizados, podemos apontar como a linguagem colonial, como o uso do termo nativos em referência ao povo, música, e produtos de nações como México e Peru, se conecta a diferentes nações da América Latina (Quadro 1). A representação de dançarinos nativos, cantores de calipso e ruínas astecas aparecem como contra-narrativas que revelam a supressão de indígenas e afrodescendentes no continente.

\section{Quadro 1. Diferenças nacionais: anglo-saxônicos versus latino-americanos}

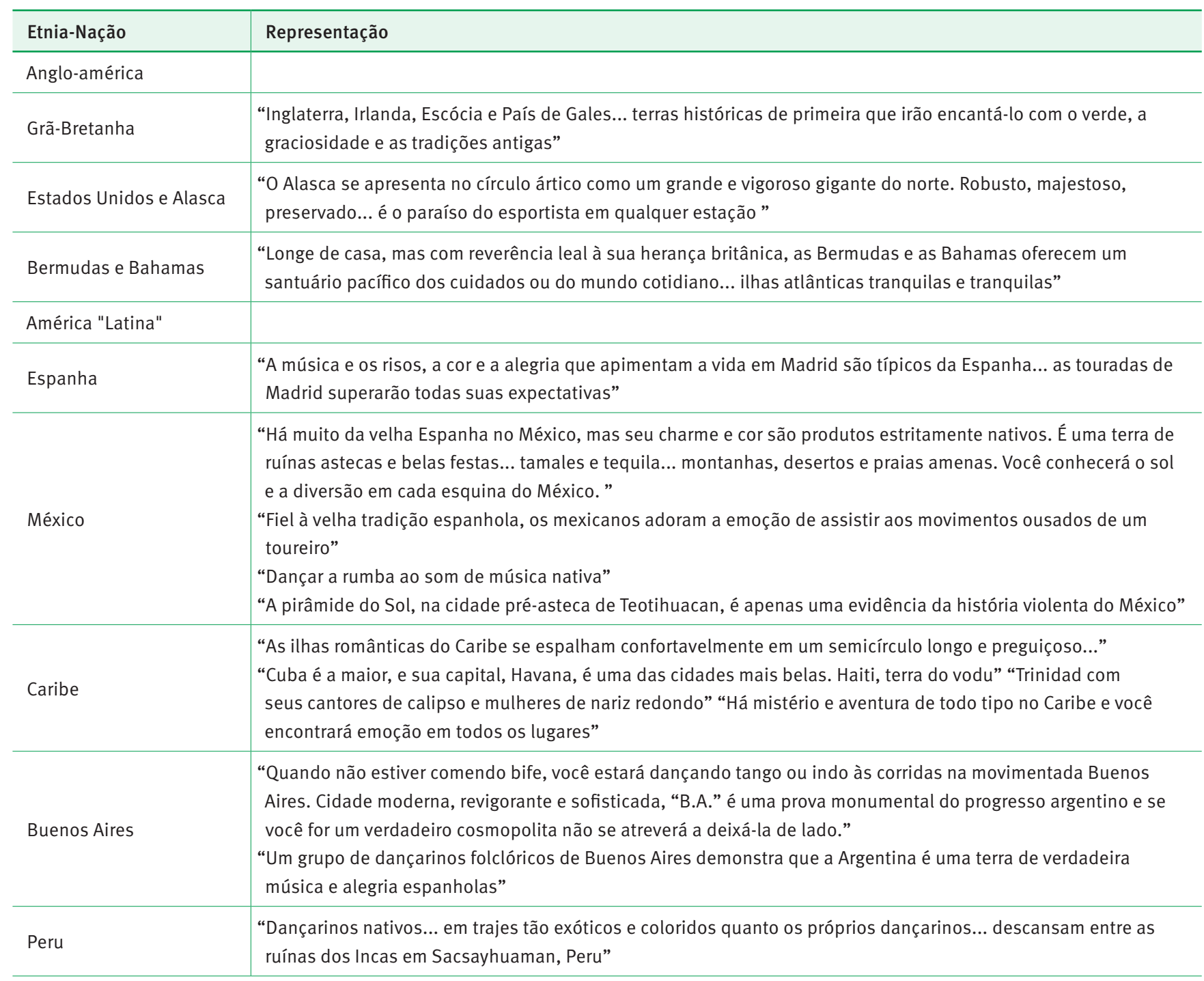

Fonte: "É um Mundo Pan-Americano" (Pan American Airways, 1952).

O legado da lenda negra (Juderías, 1914) e os estereótipos de um império espanhol atrasado, cruel e irresponsável, que foram originalmente criados pelo Império Britânico, foram transportados para as Américas e mais tarde integrados na grande narrativa 
da PAA. As representações de touradas no México carregam os velhos estereótipos usados contra os espanhóis (ou seja, bravura, crueldade e violência), enquanto ignoram histórias como a guerra EUA-México e os conflitos de fronteira que mostram que os EUA tinham características semelhantes.

Uma distinção entre as Ilhas Britânicas e o Caribe (América Latina) é retratada por meio da linguagem usada para comparar os estilos de vida de cada grupo de ilhas. As representações do Caribe referem-se à preguiça, mistério (por exemplo, vodu e magia negra), aventura e emoção da ilha. Enquanto isso, as Bermudas e as Bahamas eram descritas como santuários tranquilos, pacíficos e que têm seu próprio tempo. Essa comparação deve ser vista através do binário de racional-emocional, que há muito faz parte da ideologia moderna, europeia e ocidental. o Caribe é emocional, apaixonado e romântico, assim como os latino-americanos são românticos; no entanto, os bahamenses são calmos, racionais e centrados, como os anglo-saxões. A PAA apresenta uma visão romântica “deles”, dos outros, dos latino-americanos. 0 artigo sobre Remessas Aéreas Expressas de Miami para Caracas é um exemplo disso. Uma remessa de cordas de violão é retratada como parte da "música romântica de cordas tão valorizada pelos latino-americanos”. A narrativa a seguir expande a visão dualista entre nós - eles, América do Norte (Angloamericano) - América do Sul (Latina):

Mal sonharia o belo caballero, enquanto seus dedos dedilham as primeiras notas de sua amada dança nacional ou alguma terna serenata, que as cordas que ele toca vieram da vida prosaica da metrópole gelada do Norte para se tornar uma parte de sua música romântica sob uma lua tropical. (Pan American Airways, 1945a, p. 21)

Esta descrição combina a identidade masculina latinoamericana (por exemplo, caballeros) com uma narrativa sobre o romance e o sul tropical exótico (prosaico) em contraste com a vida cotidiana e fria da cidade do Norte.

Por último, a vida urbana na América Latina está representada em um retrato da cidade de Buenos Aires que destaca sua sofisticação e estilo de vida cosmopolita. As antinarrativas surgem como histórias alternativas, já que Buenos Aires, junto com outras cidades da América Latina, fez parte de uma narrativa que descrevia a urbanização e a modernidade de algumas nações. Nesse contexto, as nações sul-americanas eram vistas como mais progressistas e trabalhadoras do que as nações centro-americanas.

O ponto de inflexão da grande narrativa da diferença cultural ocorreu durante a Revolução Cubana (1953-1959), durante a qual a posição dominante dos Estados Unidos após a Segunda Guerra Mundial o que permitiu que governo dos EUA conduzisse uma cruzada para impedir as nações latino-americanas de aderir ao comunismo. Essa mudança foi evidenciada no diário de Betty Trippe (Pan American Airways, 1996, p. 345):

Muito se falou na festa sobre a chocante corrupção do atual ditador, o presidente Batista, e a crescente inquietação popular. Poucos meses depois, dizem alguns por influência de um repórter do New York Times, Sr. Matthews, Fidel Castro começou lentamente a formar um Partido Comunista no leste.

\section{DISCUSSÃO}

Partindo da obra de Boje (2001, 2008a, 2008b) estruturamos o material da PAA em três grandes narrativas sobre a América Latina: política, econômica e cultural. Embora delineadas como progredindo de uma para outra, essas narrativas se sobrepõem ao longo do tempo. A leitura do material da PAA por meio de lentes decoloniais mostra que o contexto histórico (1927 a 1960), como a introdução da narrativa do bom vizinho, influenciou a companhia aérea a orquestrar uma narrativa moderna sobre vizinhança e amizade. O bom vizinho fazia parte do discurso patriarcal e masculino da PAA que apadrinhava as nações latinoamericanas. Os estereótipos de gênero também eram comuns, já que a PAA exibia masculinidade através do gaúcho e do camponês moreno e feminilidade através da dançarina caribenha morena. A grande narrativa da riqueza natural revela maior interesse pela riqueza natural da América Latina e menos interesse pela amizade e como a tecnologia foi um grande motivador para a expansão da PAA. Enquanto isso, mapas de viagens e outros documentos mostram a colonialidade por meio da forma como as mulheres e os homens latino-americanos eram retratados. A grande narrativa da diferença cultural desdobra-se em duas antinarrativas nas quais as imagens racializadas e descrições dos latino-americanos, juntamente com a urbanização sul-americana, reforçam as diferenças e semelhanças entre o Anglo-americano e a América Latina.

Trabalhar com arquivos exigiu um processo iterativo de alternância entre a análise dos materiais da organização e o contexto sócio-histórico em que foram criados (Mills \& Helms Mills, 2011). As narrativas da PAA sobre a América Latina foram co-criadas (Boje, 2008b) com o governo dos Estados Unidos. Eventos como a política de Boa Vizinhança de FDR tentaram 
melhorar as relações com a América Latina, enquanto a criação de uma 'Ameaça Alemã' dentro das companhias aéreas sulamericanas na década de 1930 e na Segunda Guerra Mundial, a Guerra Fria e revoltas populares no México e Cuba (Holden \& Zolov, 2011) demonstram o aprofundamento dos assuntos entre EUA e América Latina. Enquanto isso, a expansão do PAA na parte sul da América do Norte (ou seja, primeiro México, Cuba e Colômbia), por meio do estabelecimento de escritórios, agências e investimento em infraestrutura, apoiou a presença do governo dos Estados Unidos nas nações latino-americanas (Bender \& Altschul, 1982). Ao mesmo tempo, o discurso em torno do pan-americanismo, relativo à unificação regional dos Estados Unidos vis-à-vis a América Latina, resultou no aumento da produção de representações culturais de povos latino-americanos em diferentes enclaves. Um exemplo de sua impressão inclui a iniciativa dos Estados Unidos que criou o Escritório de Coordenação de Relações Comerciais e Culturais (Office for Coordination of Commercial and Cultural Relations - OCCIA) entre as Américas. Ao escolher 1927 como ponto de partida para este estudo, pudemos ilustrar como a empresa ganhou espaço na América Latina em seus primeiros três anos de operação; encerramos o estudo na década de 1960 devido ao menor interesse dos Estados Unidos pela região após esse período (Schoultz, 1998) e devido à retomada do controle pelas repúblicas latino-americanas de muitas de suas companhias aéreas, antes cedidas para serem administradas pela PAA.

Este estudo contribui para o estudo da gestão, organizações e história ao abordar uma nova consciência histórica (Suddaby, 2016), compreender e envolver as organizações com seu passado (Lasewicz, 2015; Taylor, Bell, \& Cooke, 2009) e usar a história como um recurso estratégico (Foster et al., 2017). Nossa abordagem do passado e da história usa teorias feministas decoloniais para analisar a narrativa da PAA.

Ao usar a teoria feminista decolonial, contribuímos para o estudo da administração, história e organizações de três maneiras. Em primeiro lugar, o feminismo decolonial aumenta nossa compreensão do presente, recontextualizando o passado histórico. Assim, o estudo do feminismo decolonial nas organizações requer conhecimento de eventos históricos para ver a influência do processo de colonização na atualidade. Foi possível estudar como as relações geo-históricas entre a América Latina e os Estados Unidos (Anglo-América) se refletiram nos documentos e materiais publicitários da PAA para a América Latina. Os estereótipos raciais de latinos e latinas ilustram o legado colonial de colonos espanhóis e portugueses na América Latina versus colonos britânicos na América do Norte; os primeiros foram vistos negativamente e vistos como cruéis e irresponsáveis.
Em consonância com a 'virada histórica' na teoria organizacional e de gestão (Booth \& Rowlinson, 2006), este trabalho oferece uma explicação plausível de como as organizações se tornam (re) produtoras de colonialidade no presente, reproduzindo imagens, textos e identidades retratando o latino-americano como um americano de segunda classe (viz. Latim). Em segundo lugar, exploramos diferentes identidades sociais, tais como nação, classe e gênero por meio da narrativa patriarcal embutida no passado colonial e no presente pós-colonial. O feminismo decolonial presume que as fronteiras ilusórias permitem que aqueles no poder criem identidades sociais, e as grandes narrativas das organizações refletem noções de gênero e raça que mostram quais e como diferentes identidades sociais foram excluídas ou legitimadas. Em terceiro lugar, o feminismo decolonial propõe uma mudança na gestão, na história e nas organizações, recontextualizando, descontextualizando o passado e a narrativa hegemônica embutida nas grandes narrativas das organizações.

Por fim, este artigo é uma obra política que contribui para as literaturas decoloniais e feministas que abordam criticamente as representações históricas da América Latina. Nos inspiramos em Anzaldúa (2007) e sua abordagem do feminismo e do colonialismo, e isso guiou esta pesquisa pelo caminho da consciência decolonial. Esta obra é decolonial no campo dos estudos de gestão e organizações, pois levanta questões críticas sobre raça e gênero, ao mesmo tempo que permite que a voz de uma de suas autoras, uma mulher sul-americana, mestiça, seja incluída como uma das narradoras. 0 pensamento de fronteira (Anzaldúa, 2007; Mignolo, 2000) é uma ferramenta poderosa para repensar as histórias organizacionais na pesquisa qualitativa.

\section{REFERÊNCIAS}

Alcadipani, R., \& Faria, A. (2014). Fighting Latin American marginality in "international" business. Critical Perspectives on International Business 10(1/2), 107-117. doi: 10.1108/cpoib-11-2013-0047

Anzaldúa, G. (2007). Borderlands/LaFrontera: The new mestiza (3rd ed.). San Francisco, USA: Aunt Lute Books.

Bender, M., \& Altschul, S. (1982). The chosen instrument Pan Am, Juan Trippe, the rise and fall of an American entrepreneur. Retrieved from http://books.google.com/books?id=CoJPAAAAMAAJ

Bethell, L., \& Roxborough, I. (1988). Latin America between the Second World War and the Cold War: Some reflections on the 1945-8 conjuncture. Journal of Latin American Studies, 20(1), 167-189. doi: 10.1017/So022216X00002522Pub

Boje, D. M. (2001). Narrative methods for organizational and communication research. Thousand Oaks, USA: SAGE. 
Boje, D. M. (2008a). Antenarrative. In R. Thorpe \& R. Holt (Eds.), The Sage dictionasry of qualitative management research. London, UK: SAGE. 28-30.

Boje, D. M. (2008b). Storytelling organizations. London, UK; Thousand Oaks, USA: SAGE.

Booth, C., \& Rowlinson, M. (2006). Management and organizational history: Prospects. Management \& Organizational History, 1(1), 5-30. doi: $10.1177 / 1744935906060627$

Calás, M., Ou, H., \& Smircich, L. (2013). "Woman" on the move: Mobile subjectivities after intersectionality. Equality, Diversity \& Inclusion, 32(8), 708-731. doi: 10.1108/EDI-05-2012-0037

Decker, S. (2013). The silence of the archives: Business history, postcolonialism and archival ethnography. Management \& Organizational History, 8(2), 155-173. doi: 10.1080/17449359.2012.761491

Durepos, G., Helms Mills, J., \& Mills, A. J. (2008). Flights of fancy: Myth, monopoly and the making of Pan American Airways. Journal of ManagementHistory,14(2), 116-127. doi 10.1108/17511340810860249

Erel, U., Haritaworn, J., Gutierrez Rodriguez, E. , \& Klesse, C. (2011). On the depoliticisation of intersectionality talk: Conceptualising multiple oppressions in critical sexuality studies. In Y. Taylor, S. Hines, \& M. E. Casey (Eds.), Theorizing intersectionality and sexuality (pp. 56-77). Basingstoke, UK: Palgrave Macmillan.

Foster, W. M., Coraiola, D. M., Suddaby, R., Kroezen, J., \& Chandler, D. (2017). The strategic use of historical narratives: A theoretical framework. Business History, 59(8), 1176-1200. doi: 10.1080/00076791.2016.1224234

Gantman, E. R., Yousfi, H., \& Alcadipani, R. (2015). Challenging AngloSaxon dominance in management and organizational knowledge. RAE-Revista de Administração de Empresas, 55(2), 126-129. doi: 10.1590/S0034-759020150202

Hedstrom, M. (2002). Archives, memory, and interfaces with the past. Archival Science, 2(1-2), 21-43. doi: 10.1023/A:1020800828257

Holden, R. H., \& Zolov, E. (2011). Latin America and the United States: A documentary history. New York, USA: Oxford University Press.

Ibarra-Colado, E. (2006). Organization studies and epistemic coloniality in Latin America: Thinking otherness from the margins. Organization, 13(4), 463-488. doi: 10.1177/1350508406065851

Ibarra-Colado, E. (2008). Is there any future for critical management studies in Latin America? Moving from epistemic coloniality to "trans-discipline'. Organization, 15(6), 932-935. doi: 10.1177/1350508408095822

Interdepartmental Committee on Cooperation with the American Republics. (1940, January 17). Report of the Interdepartmental Committee on Cooperation with the American Republics. Franklin D.Roosevelt Presidential Library and Museum archives.

Juderías, J. (1914). La leyenda negra y la verdad histórica. Madrid, España: Tip. de la "Rev. de Arch., Bibl. y Museos".

Lasewicz, P. C. (2015). Forget the past? Or history matters? Selected academic perspectives on the strategic value of organizational pasts. The American Archivist, 78(1), 59-83. doi: 10.17723/0360-9081.78.1.59

Lugones, M. (2015). Hacia metodologías de la decolonialidad. In Leyva, X. J. Alonso, A. Hernández, A. Escobar, A. Köhler, A. Cumes, \& W. Mignolo (Eds.), Prácticas otras de conocimiento (s): Entre crisis y guerras. (Tomo III). México, Cooperativa Editorial RETOS, Taller Editorial La Casa del Mago, CLACSO, 3 tomos. Retrieved from: http://biblioteca.clacso. edu.ar/clacso/se/20180515110853/Practicas_Otras_2.pdf
Lyotard, J.-F. (1987). La condicion postmoderna: Informe sobre el saber. Madrid, España: Editions de Minuit.

Mignolo, W. D. (2000). Local histories/global designs: Coloniality, subaltern knowledges, and border thinking. Princeton, USA: Princeton University Press.

Mignolo, W. D. (2002). The geopolitics of knowledge and the colonial difference. South Atlantic Quarterly, 101(1), 57-96. doi: 10.1215/00382876-101-1-57

Mignolo, W. D. (2005). The idea of Latin America. Oxford, UK: WileyBlackwell.

Mignolo, W. D. (2007). Delinking the rhetoric of modernity, the logic of coloniality and the grammar of de-coloniality. Cultural Studies, 21(2), 449-514. doi: 10.1080/09502380601162647

Mignolo, W. D. (2011). The darker side of Western modernity: Global futures, decolonial options. Durham, USA: Duke University Press.

Mignolo, W. D., \& Tlostanova, M. V. (2006). Theorizing from the borders: Shifting to geo- and body-politics of knowledge. European Journal of Social Theory, 9(2), 205-221. doi: 10.1177/1368431006063333

Mills, A. J. (2010). Juncture. In A. J. Mills, G. Durepos, \& E. Wiebe (Eds.), Encyclopedia of case study research (pp. 509-511). Thousands Oaks, USA: Sage.

Mills, A. J., \& Helms Mills, J. (2011). Digging archaeology: Postpositivist theory and archival research in case study development. In R. Piekkari \& C. Welch (Eds.), Rethinking the case study in international business and management research (pp. 342-360). Northampton, USA: Edward Elgar Publishing.

Mills, A. J., \& Helms Mills, J. (2017). Archival research. In C. Cassell, A. L. Cunliffe, \& G. Grandy (Eds.), The SAGE Handbook of qualitative business and management research methods(pp.32-45). London, UK: Sage.

Miñoso, Y. E., \& Castelli, R. (2011). Colonialidad y dependencia en los estudios de género y sexualidad en América Latina: El caso de Argentina, Brasil, Uruguay y Chile. In K. Bidaseca \& V. Vazquez Laba (Eds.), Feminismos y poscolonialidad: Descolonizando el feminismo desde y en América Latina, (pp.191-214). Buenos Aires, Argentina: Ediciones Godot.

Mohanty, C. T. (1984). Under western eyes: Feminist scholarship and colonial discourses. Boundary 2, 12/13(3/1), 333-358. doi: $10.2307 / 302821$

Mohanty, C. T. (1991). Cartographies of struggle: Third World women and the politics of feminism. In C. T. Mohanty, A. Russo, \& L. Torres (Eds.), Third World women and the politics of feminism (pp. 1-47). Bloomington, USA: Indiana University Press.

Mohanty, C. T. (2003). Feminism without borders: Decolonizing theory, practicing solidarity. Durham, USA: Duke University Press.

Mohanty, C. T. (2008). Women workers and capitalist scripts: Ideologies of domination, common interests, and the politics of solidarity. In A. Bailey \& C. J. Cuomo (Eds.), The feminist philosophy reader (pp. 379400). Boston, USA: McGraw-Hill.

Pan American Airways. (1943). The wealth of the Other Americas (Series 17, Collection ASM0341, pp. 1-39). Pan American World Airways, Inc. Records, Special Collections, University of Miami Libraries, Coral Gables, USA. 
Pan American Airways. (1945a). The flying clippers in the Southern Americas (Series 17, Subseries 3, Subseries 20, Box 8, Collection ASB0341). Pan American World Airways, Inc. Records, Special Collections, University of Miami Libraries, Coral Gables, USA.

Pan American Airways. (1945b). Pan American clipper (Vol. 1, N. 8, Series 17, Subseries 3, Subseries 91, Box 49, Collection ASB0341). Pan American World Airways, Inc. Records, Special Collections, University of Miami Libraries, Coral Gables, USA.

Pan American Airways. (1945c). Ten thousand times around the world (Box 625, Folder 46, Collection ASB0341). Usher, Donald K. Pan American World Airways, Inc. Records, Special Collections, University of Miami Libraries, Coral Gables, USA.

Pan American Airways. (1946a). Article in The Wall Street Journal. Pan American Airways, pioneer in foreign field, becomes first carrier certified to fly around world (Series 4, Subseries 17, Box 1, Collection ASB0341). Pan American World Airways, Inc. Records, Special Collections, University of Miami Libraries, Coral Gables, USA.

Pan American Airways. (1946b). Pan American clipper (Vol. 2, N. 7, Box 82, Folder 10, Collection ASB0341). Pan American World Airways, Inc. Records, Special Collections, University of Miami Libraries, Coral Gables, USA.

Pan American Airways. (1946c). Pan American clipper (Vol. 2, N. 13, Box 82, Folder 10, Collection ASB0341). Pan American World Airways, Inc. Records, Special Collections, University of Miami Libraries, Coral Gables, USA.

Pan American Airways. (1946d). A world of neighbors (Series 17, Subseries 1, Collection ASB0341). Pan American World Airways, Inc. Records, Special Collections, University of Miami Libraries, Coral Gables, USA.

Pan American Airways. (1952). It's a Pan American world (Collection 341, Printed Material Pan Am - Brochures - Others). Miami, USA: Otto Richter Library, University of Miami.

Pan American Airways. (1957b). Barbados advocate P.A.A. supplement (Series 4, Subseries 17, Box 1, Collection ASMo341). Pan American World Airways, Inc. Records, Special Collections, University of Miami Libraries, Coral Gables, USA.

Pan American Airways. (1958). A story of people, opportunities, and services (Series 17, Subseries 1, Subseries 2, Collection ASM0341). Pan American World Airways, Inc. Records, Special Collections, University of Miami Libraries, Coral Gables, USA.
Pan American Airways. (1961). Observations on US policy toward Latin America (LAD CUBA (Series 17, Subseries 3, Subseries 20, Box 8, Collection ASBo341). Pan American World Airways, Inc. Records, Special Collections, University of Miami Libraries, Coral Gables, USA.

Pan American Airways. (1996). Draft of Pan Am's first lady: The diary of Betty Stettinius Trippe (Series 6, Subseries 3, Box 20, Folder 130 9: 50.20. 02, Collection ASM0341). Pan American World Airways, Inc. Records, Special Collections, University of Miami Libraries, Coral Gables, USA.

Pan American Airways advertisement. (1941). The good neighbor who calls every day. Retrieved from library.duke.edu/digitalcollections/ adaccess

Patel, K. K. (2016). The New Deal: A global history. Princeton, USA: Princeton University Press.

Roorda, E. P. (1998). The cult of the airplane among U.S. military men and Dominicans during the U.S. occupation and the Trujillo Regime. In G. M. Joseph, C. LeGrand, \& R. D. Salvatore (Eds.), Close encounters of empire: Writing the cultural history of U.S.-Latin American relations (pp. 269-310). London, UK, and [North Carolina],USA: Chapel Hill: Duke University Press.

Salvatore, R. (1998). The enterprise of knowledge: Representational machines of informal empire. In G. M. Joseph, C. LeGrand, \& R. D. Salvatore (Eds.), Close encounters of empire: Writing the cultural history of U.S.-Latin American relations (pp. 69-104). London, UK, and [North Carolina], Chapel Hill: Duke University Press.

Schoultz, L. (1998). Beneath the United States: A history of U.S. policy toward Latin America. Massachusetts, USA: Harvard University Press.

Suddaby, R. (2016). Toward a historical consciousness: Following the historic turn in management thought.M@n@gement, 19(1), 46-6o.

Taylor, S., Bell, E., \& Cooke, B. (2009). Business history and the historiographical operation. Management \& Organizational History, 4(2), 151-166. doi: 10.1177/1744935909102906

Vaara, E., \& Tienari, J. (2011). On the narrative construction of multinational corporations: An antenarrative analysis of legitimation and resistance in a cross-border merger. Organization Science, 22(2), 370-390. doi: 10.1287 /orsc. 1100.0593

Van Vleck, J. (2013). Empire of the air: Aviation and the American ascendancy. Massachusetts, USA: Harvard University Press.

White, H. (2009). The content of the form: Narrative discourse and historical representation. Johns Baltimore, USA: Hopkins University Press.

\section{CONTRIBUIÇÃO DOS AUTORES}

Os autores declaram que participaram de forma conjunta na revisão final do texto, mas individualmente trabalharam na conceitualização e abordagem teórica-metodológica, bem como na revisão teórica (levantamento de literatura), coleta de dados, bem como na análise de dados e, por fim, redação e revisão final do artigo. 